\title{
Fund Network Centrality, Hard-to-Value Portfolio, and Investment Performance
}

\author{
Xiao Hu $\mathbb{D}^{1},{ }^{1}$ Yimeng Cang $\left(\mathbb{D},{ }^{1}\right.$ Long Ren $\mathbb{D}^{2},{ }^{2}$ and Jun Liu $\mathbb{D}^{3}$ \\ ${ }^{1}$ School of Finance, Southwestern University of Finance and Economics, Chengdu 611130, China \\ ${ }^{2}$ School of Information Technology and Management, University of International Business and Economics, Beijing 100029, China \\ ${ }^{3}$ International Business School, Beijing Foreign Studies University, Beijing 100089, China
}

Correspondence should be addressed to Jun Liu; liuj@bfsu.edu.cn

Received 14 October 2020; Revised 20 November 2020; Accepted 30 November 2020; Published 17 December 2020

Academic Editor: Abd E.I.-Baset Hassanien

Copyright (c) 2020 Xiao Hu et al. This is an open access article distributed under the Creative Commons Attribution License, which permits unrestricted use, distribution, and reproduction in any medium, provided the original work is properly cited.

\begin{abstract}
Based on the quarterly data of mutual funds in China from the fourth quarter of 2004 to the fourth quarter of 2019, this paper constructs a series of complex bipartite networks based on the overlapped portfolios of mutual funds and then explores the influences of fund network position on mutual fund's investment behavior and performance. This paper finds that a mutual fund with shorter information transmission path to other entities in the fund network (i.e., having higher closeness centrality) or with stronger ties with those entities in important information positions (i.e., having higher eigenvector centrality) will achieve better investment performance. However, a stronger mediating role over the potential information flow of the fund network (i.e., having higher betweenness centrality) cannot help a mutual fund increase performance. The empirical results also indicate that a mutual fund holding stock portfolios with high valuation difficulties caused by the market or fundamental information uncertainty will achieve better investment performance, while holding hard-to-value portfolios caused by limited public information will reduce the performance of the fund. Furthermore, high closeness centrality or eigenvector centrality can help mutual funds deal with the disclose problems of public information, thus reducing the likelihood of a mutual fund holding hard-to-value portfolios caused by limited public information to achieve worse performance. Eigenvector centrality brings information advantages about company fundamentals, so it is easier for a mutual fund with high eigenvector centrality to profit from holding hard-to-value portfolios caused by the fundamental information uncertainty. The conclusions of this paper can enhance our understanding of the fund network and its information mechanism and shed new light on mutual fund's information advantages and related asset allocation strategies.
\end{abstract}

\section{Introduction}

Investors need to rely on information to make investment decisions. Since mutual funds are main institutional investors in the capital market, how they obtain and use information advantages have attracted scholars' attention. Many studies indicate that information advantages help mutual funds improve investment performance [1-4].

One important way for a mutual fund to gain information advantages is through the fund network. The network reflects a collection of social interaction relations and provides a channel for information transmission among social actors [5-10]. A mutual fund is embedded in a certain network where it directly or indirectly associates with other entities [11-13]. Therefore, it can obtain valuable information related to investment by interacting with others in the fund network, thus shaping their investment strategies and returns $[14,15]$. In other words, the fund network exerts influences on mutual funds through the information mechanism of the network [16].

A network structure consists of nodes and edges, in which the nodes are actors in social interactions and the edges are the connections between nodes through such social activities [5]. From the perspective of network embeddedness, each node in the network plays the two roles of the mediator and filter, for network information flows [17]. Thus, the location of a node in the network determines the quantity and quality of information; it can access from the network [9] 
as well as has the ability to address information [18]. Accordingly, a better-networked mutual fund with a more influential position in the fund network may occupy more information advantages, which can improve its investment performance. Graph theory provides us with tools for measuring the importance of the network position of each node relative to other nodes. The tools mainly involve four network indicators: degree centrality, closeness centrality, betweenness centrality, and eigenvector centrality. These four kinds of network centrality have different definitions. Degree centrality is the simplest indicator and counts the number of direct ties of a focal network node [19]. The nodes directly connected with more nodes have more channels to obtain information and obviously have more favorable network positions. Closeness centrality is the reciprocal of the average shortest path of a focal node's access to other nodes directly or indirectly in the network [20]. It shows the connectivity of a node in the network and can reflect the efficiency of the node to obtain information by using its network location. Betweenness centrality measures the possibility that a focal node lies on the shortest path of any two other nodes, so it can indicate the mediating role over the potential information flows in the network that the focal node plays [21]. Eigenvector centrality is calculated from the eigenvectors of the network adjacency matrix and represents the degree to which a focal node builds ties with influential nodes in the network [22]. Most literature studies on the position of mutual fund in the fund network focus on degree centrality $[12,23]$ and support that degree centrality could improve fund performance [24]. However, degree centrality neither considers the indirect ties in the fund network nor can capture the network structural characteristics contained in the other three centrality indicators. To this end, this paper explores the influences of closeness centrality, betweenness centrality, and eigenvector centrality of fund network on fund performance, especially compares the differences in the effects of the three network centrality indicators.

Although previous studies analyze the relationship between fund network and fun performance based on the information functions of the network $[11,25]$, the underlying mechanism by how the information advantages brought by the network position help a mutual fund improve investment performance has not been examined. This paper tries to deal with the research gap by testing the impacts of a mutual fund's network centrality on the performance of its investment behaviors. Specifically, we focus on the investment behavior in which mutual funds allocate stocks with high valuation difficulty. High information uncertainty, poor disclosure, or low quality of public information will increase the difficulty of stock valuation, causing it hard for mutual funds to make accurate predictions on such stocks [26-28]. Holding hard-to-value stock portfolios require mutual funds to have stronger capabilities of information mining and analysis to reduce investment risks. Moreover, hard-to-value stocks are more likely to be mispriced, so they always have richer arbitrage opportunities [29-37]. The information advantages possessed by better-networked mutual funds may help generate greater returns from the hard-to-value portfolios.
Using the quarterly data of China's mutual funds from the fourth quarter of 2004 to the fourth quarter of 2019, this paper explores three important questions: (i) how closeness centrality, betweenness centrality, and eigenvector centrality in fund network impact mutual fund's investment performance, respectively; (ii) how holding hard-to-value portfolio impacts mutual fund's investment performance; (iii) how the information advantages brought by the three network centrality indicators impact mutual fund's return from the hard-to-value portfolio.

\section{Hypothesis Development}

2.1. Fund Network Centrality and Investment Performance. Network centrality reflects the importance of the network position of each node relative to other nodes. We argue that a mutual fund with higher centrality in the fund network can achieve better investment performance. There are two main reasons. First, a mutual fund centrally located in the fund network can connect with other entities through fewer intermediaries; this can improve their efficiency and reduce their costs to acquire information from the fund network and help them overcome the information constraints that other entities impose [38]. In addition, the more influential the position of a mutual fund occupies in its network, the higher the level of involvement it has in the information flow through direct or indirect ties with others $[39,40]$. This will help the mutual fund access more information sources $[41,42]$ while also ensuring the quality of information by comparing different sources [18].

It also should be noted that closeness centrality, betweenness centrality, and eigenvector centrality captures different structural features of the fund network, so they may have different influences on mutual funds. Closeness centrality reflects the length of the information transmission path between a mutual fund and other entities in the fund network [43]. Betweenness centrality reflects the mediating effect of a mutual fund on the potential information flow in the fund network [44]. Eigenvector centrality in the fund network reflects the degree of relationships between a mutual fund and other entities in important information positions [45]. Therefore, we believe that the three types of network centrality bring different information advantages to mutual funds. As such, Hypothesis 1 is as follows.

Hypothesis 1. A mutual fund with a more central position in the fund network will achieve better investment performance, but the effects of closeness centrality, betweenness centrality, and eigenvector centrality could be different.

2.2. Hard-to-Value Portfolio and Investment Performance. Stocks with higher valuation difficulty have less public information, less transparency, and more information uncertainty, and meanwhile, their related indicators such as company fundamentals and market sentiment have higher volatility. Because hard-to-value stocks are more likely to be mispriced, mutual funds may use the potential arbitrage opportunities to achieve better performance. According to 
Lai et al. [36] and Kumar [33], mature institutional investors have advantages in terms of analytical capability and information acquisition, so they are more likely to make profits by taking advantage of pricing errors when information is uncertain. Chen et al. [46] study the trading situations of active funds and point out that the trading behavior of a fund reflects the fund's ability to identify mispriced stocks. Therefore, we argue that mutual funds are more likely to profit from their active allocation on hard-to-value portfolios.

There are three main reasons for the valuation difficulty of stocks, generating three types of hard-to-value portfolios. The first is caused by market information uncertainty. Although the trading price of a stock can be observed by investors, the high volatility and low synchronicity of its price make it difficult to be evaluated [33]. The second is caused by fundamental information uncertainty. Good financial condition and corporate governance of a listed company are helpful for mutual funds to accurately analyze its fundamentals with public information [27]. The third is caused by limited public information. The disclosure of a listed company's public information such as annual reports and research reports provided by third-party institutions also affects its valuation difficulties [47]. The information attributes behind the three types of hard-to-value portfolios are different. In such cases, we propose Hypothesis 2 as follows.

Hypothesis 2. Holding hard-to-value portfolios can help a mutual fund achieve better investment performance, but there could be different returns of the hard-to-value portfolios caused by market information uncertainty, fundamental information uncertainty, or limited public information.

\subsection{Fund Network Centrality and Return of Hard-to-Value} Portfolio. Holding hard-to-value portfolios require mutual funds to have stronger capabilities of information mining and analysis to reduce investment risks and take full use of the potential arbitrage opportunities. Mutual funds with strong information advantage are abler to make profits from the portfolios with high valuation difficulty. Since closeness centrality, betweenness centrality and eigenvector centrality bring some information advantages to a mutual fund, they will affect the mutual fund's information mining and information analysis $[3,4]$, thereby influencing the returns of hard-to-value portfolios. Further considering the different information advantages brought by the three-fund network centrality indicators and the different information attributes of the three types of hard-to-value portfolios, Hypothesis 3 is proposed as follows:

Hypothesis 3. Fund network centrality increases the likelihood for a mutual fund to achieve better investment performance by holding hard-to-value portfolios, but the three centrality indicators could have different influences on the returns of the three types of hard-to-value portfolios.

\section{The Data}

This paper uses open-ended stock funds or stock-leaning funds which execute active strategies in China as the research object. Although our empirical data is about Chinese mutual funds, we do not want to highlight the Chinese research context too much but try to make general contributions to existing studies. Admittedly, as an emerging market, China's stock market has higher information uncertainty [48], more mispricing phenomena [49], and speculative investment behaviors than mature markets [50]. It may be more effective for Chinese mutual funds to use a fund network and invest hard-to-value stocks to improve investment performance. However, previous studies also indicate that even the mature capital markets of developed countries cannot reach the standard of weak efficiency, so stronger capabilities of information mining and analysis can help fund managers to achieve better performance [51]. Besides, a fund network has been proven to exist in mature markets and can be an important way for mutual funds to obtain information advantages [24]. To this end, the Chinese market is just an appropriate research context where information is more valuable for investment, and the conclusions are drawn from the market and still have applicability to other markets.

Since China's open-ended fund market was formed at the end of 2004, the sample period is from the fourth quarter of 2004 to the fourth quarter of 2019. We exclude funds that are Shanghai-Hong Kong Stock Connect funds and Qualified Domestic Institutional Investor (QDII) from our samples because these funds may invest overseas stocks which could bring difficulties for us to construct fund networks and compare investment behaviors and performance among funds. To eliminate the possible interferences of mutual funds' initial investment period of building up positions, mutual funds established less than one year are further excluded. When constructing quarterly fund networks, several mutual funds cannot access any other funds in the networks because their portfolios have no overlaps with others. Calculating the centrality of unconnected networks may distort the indicators of corresponding nodes, so we only retain the mutual funds in the largest connected networks. The final sample contains 2,802 funds and 37,607 fund-quarter observations.

The data of each mutual fund's quarterly portfolios and other details about the fund manager, fund financial statement, and trading information are obtained from the mutual fund's first quarter, semiannual, third quarter, and annual reports collected by the CSMAR database. We obtain most of the stock data such as ROE ROA, operating income, market value, and daily stock price from the RESSET database. Other data used in the paper such as audit data and securities analyst data of each stock are from the CNRDS database.

\section{Fund Network Construction}

Previous studies employ three methods to construct the fund network. The first is to define network ties based on the same 
education or career background of fund managers. For example, Shen [25] indicates that the alumni network enables fund managers to obtain private information, thus promoting the performance of the fund. The second is to define network ties based on the geographical location of fund managers. Hong et al. [11] find that geographic proximity would make it possible for individuals to exchange more information, so the trading behavior of a fund manager would be significantly affected by other fund managers in the same city. The above two types of fund network are intuitive, but the information transmission in the network cannot be observed directly because the ties between mutual funds are defined from communication sources. The relations based on geographical location or background do not mean that fund managers actually have access to information exchanges that can influence their investment decisions.

In this regard, some scholars construct the fund network from the overlapped portfolios of mutual funds. According to Bushee and Goodman [14], Jiang [15], and Cohen et al. [52], when a mutual fund holds a certain stock in a large position, it means that the mutual fund may own more information of that stock. Shiller and Pound [53] believe that a mutual fund may have some information exchange with other mutual funds which hold the same stocks, and its investment decisions are influenced by them. Pareek [12] indicates that mutual funds who hold the same stocks show significantly consistent investment behavior, which could not be explained by the funds' investment style and geographical location. To some extent, the fund network based on the overlapped portfolios of mutual funds is not limited to a certain type of information connection because it covers the possible information exchanges brought by geographical proximity or the same background. In other words, if the information advantages obtained from others who have a near geographical location or the same background can influence a fund manager's investment decision, it will eventually be reflected in the portfolio behavior of the fund manager. In addition, the fund shareholding network shows the relations between mutual funds established by their overlapped portfolios, which is more directly related to mutual funds' investment behaviors and performance. Compared with the other two kinds of fund networks, the fund shareholding network may be a more significant driven factor for fund behavior and performance.

Expect for the social relations between mutual funds, mutual funds and stocks they hold may interact with each other $[54,55]$. Cohen et al. [56] indicate that fund managers are more willing to invest in stocks whose executives have the same education experience. Frankel et al. [57] find that, during the teleconference, there are increasing volume and price volatility of the listed company's stock because institutional investors may use the message of the teleconference for trading. Since mutual funds can both obtain information about stock from other mutual funds and listed companies, we use a bipartite network approach to comprehensively describe the information channels of mutual funds [58].

In bipartite networks, actors of a common nature are linked through their joint actions known as events, and the events themselves exist in the network as nodes. When two mutual funds invest in the same stock, the stock acts as an event node that can link the two funds. The bipartite network method helps us capture the interdependencies between the mutual funds and the stocks [59] and can reflect the information advantages of mutual funds obtained from the two sources of listed companies and mutual funds. Specifically, we define two types of nodes: mutual funds and stocks. At the end of each quarter, if the market value of a stock held by a mutual fund accounts for more than $5 \%$ of its position 1 , a tie is established between them. When we take each stock as a subset of a group of funds, a bipartite network at that time is constructed.

Figure 1 shows the bipartite network on 31 March 2005. The blue nodes represent mutual funds, and the white nodes represent stocks. The edges between a blue node and a white node indicate that a fund holds stock in more than $5 \%$ of its position. Figure 2 is a part of the network in Figure 1 and shows all direct connections of fund 040002 (the red node). The mutual fund held five stocks (i.e., 000792, 000402, 000538, 000866, and 600096) in a large position. The five stocks were the main holdings of the other 25 funds. In other words, there were connections for Fund 04002 to the 25 funds through the five stocks in its portfolio.

\section{Measurement}

5.1. Investment Performance. Following the method of Agarwal et al. [60], we use Alpha after risk adjustment for the four-factor model to measure the investment performance of mutual funds [61]. In the first step, the monthly return rate of the previous 24 months of mutual fund $j$ is used for regression to calculate the four-factor parameters. The regression equation is as follows:

$$
R_{i, s}=\widehat{\alpha}_{i, t-1}+\sum_{k=1}^{4} \widehat{\beta}_{i, k, t-1} F_{k, s}+\varepsilon_{i, s}, \quad s=m-24, \ldots, m-1,
$$

where $s$ and $m$ stand for month, $R$ stands for fund i's the monthly return on net value excluding the risk-free interest rate, And $F$ stands for monthly four factors (i.e., market risk premium factor, market value factor, book value factor, and momentum factor).

The monthly excess return rate of the fund is calculated by the following formula:

$$
\text { Performance }_{i, m}=R_{i, m}-\sum_{k=1}^{4} \widehat{\beta}_{i, k, m-1} F_{k, m} \text {. }
$$

5.2. Closeness Centrality. In a one-mode network, closeness centrality is the reciprocal of the average shortest path of focal node access to other nodes in the network. According to Faust [62], the actor nodes of a bipartite network are only adjacent to event nodes, and all paths emanating from an actor must first pass through the events to which the actor belongs. To this end, the closeness centrality of mutual fund $i$ 


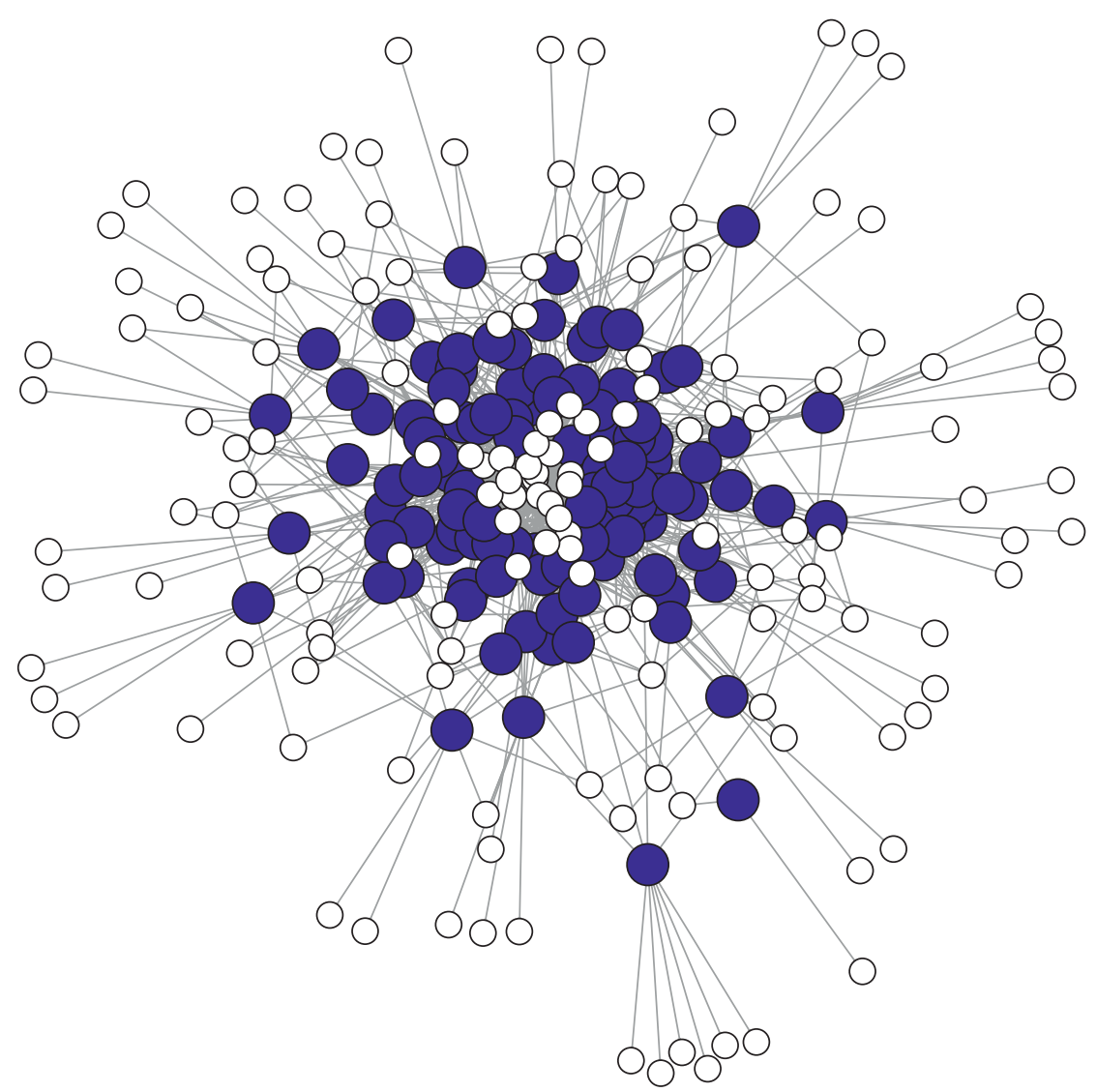

Figure 1: The bipartite network on 31 March 2005.

in our bipartite network is a function of the minimum distances from any of its stocks and to other funds and stocks in the network:

$$
\text { Closenss }_{i}=\left[1+\frac{\sum_{j=1}^{g+h} \min _{k} d(k, j)}{g+h-1}\right]^{-1},
$$

where $k$ are the stocks connected to fund $i, d(k, j)$ represents the minimum distance between stocks $k$ and other funds or stocks in the network, and $g$ and $h$, respectively, represent the number of funds and stocks.

5.3. Betweenness Centrality. Betweenness centrality for a one-mode dyadic network focuses on the extent to which nodes sit on geodesic paths between other pairs of nodes [21]. In a bipartite network, linkages between pairs of event nodes are always through the joint memberships of actor nodes, thus actor nodes are always on paths between events. In calculating the betweenness centrality of mutual fund $i$, in a bipartite network, we focus on the collection of stocks that belong to the fund. Fund $i$ is on a path between all pairs of actors that are members of it. If a given pair of stocks, $(l, k)$, only shares fund $i$ in common (thus $x_{k l}^{M}=1$ ), then fund $i$ is on the only path between them, and fund $i$ 's betweenness centrality is incremented by $\left(1 / x_{k l}^{M}\right)$ for each pair of stocks $(l$, $k$ ) in fund $i$. Thus, a portion of the betweenness centrality of fund $i$ can be expressed as follows:

$$
\text { Betweenness }_{i}=\frac{1}{2} \sum_{m_{k}, m_{l} \in n_{i}} \frac{1}{x_{k l}^{M}} .
$$

In addition, an event gains betweenness centrality if a stock belongs only to fund $i$. In that case, all paths from the stock must contain the fund. Since there are $g+h$ nodes (funds and stocks) in the bipartite network, a fund gains $g+h-2$ betweenness centrality points' for each of its members that belong to no other funds. This quantity is not independent of the count in equation (4).

5.4. Eigenvector Centrality. Eigenvector centrality provides a measure of the extent to which a focal node builds ties with influential nodes in the network [22]. Bonacich [63] shows that, for a bipartite network, the eigenvector centrality of actor nodes and event nodes can be derived from the following equation:

$$
\lambda\left[\begin{array}{l}
\mathbf{c}^{N} \\
\mathbf{c}^{M}
\end{array}\right]=\left[\begin{array}{cc}
0 & \mathbf{A} \\
A^{\prime} & 0
\end{array}\right]\left[\begin{array}{l}
\mathbf{c}^{N} \\
\mathbf{c}^{M}
\end{array}\right],
$$

where $A=\left\{a_{i j}\right\}(i=1,2, \ldots, g$ and $j=1,2, \ldots, h)$ is denoted as the adjacency matrix between actor nodes and event nodes. $g$ and $h$ are the number of actor nodes and event nodes, respectively. $\lambda$ is the largest eigenvalue of matrix $\mathbf{A} \cdot \mathbf{c}^{N}$ and $\mathbf{c}^{M}$ are the eigenvectors corresponding to the largest eigenvalue for actor nodes and event nodes, respectively. 


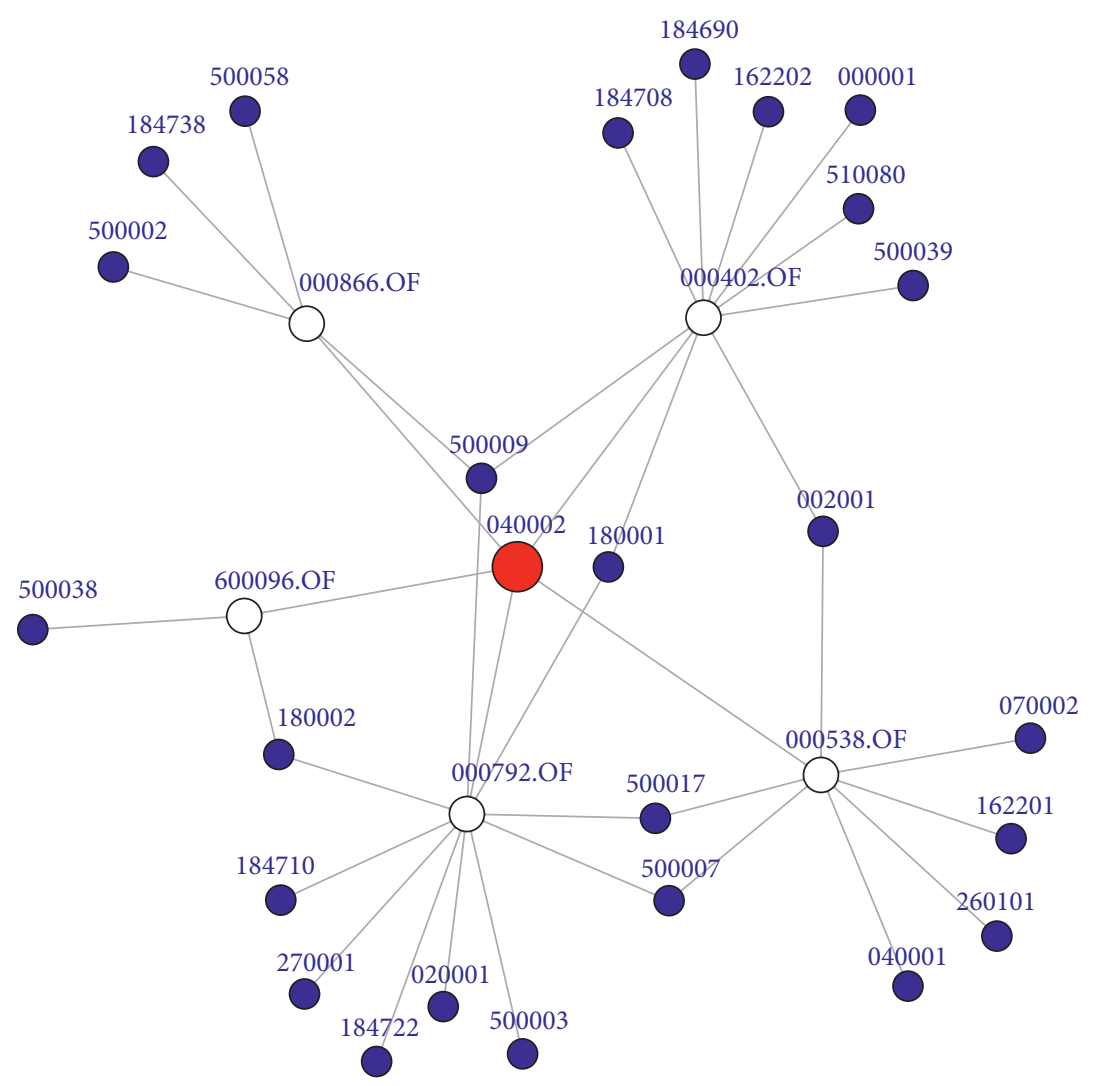

Figure 2: The connections of fund 040002 (the red node) on 31 March 2005.

When we denote $\mathbf{A}$ as the adjacency matrix between mutual funds and stocks, the eigenvector centrality of mutual fund $i$ (Eigenvector ${ }_{i}$ ) can be obtained from the vector of eigenvector centrality scores for funds $\mathrm{c}^{N}$.

\subsection{Hard-to-Value Portfolio Caused by Market Information} Uncertainty. We use four indicators to measure the hard-tovalue portfolio caused by market information uncertainty. The first indicator is stock price volatility, which is obtained by dividing the standard deviation of a stock's weekly return rate in the half-year formative period by its initial stock price. The second indicator is the stock characteristic volatility. A Fama-French three-factor model is used to carry out regression on the weekly return series of the formative period, and the standard deviation is calculated from the residual. The two indicators reflect information uncertainty. High stock price volatility and characteristic volatility may increase the valuation difficulty of a stock.

The third indicator is the $R^{2}$ of the regression results using asset pricing model. The following equation shows the regression with the data of the weekly return rate:

$$
r_{i, t}=\alpha_{i}+\beta_{i} r_{m, t}+c_{i} I_{i, t}+e_{i, t}
$$

where $r_{i, t}$ is the return rate of stock $i$ in week $t, r_{m, t}$ stands for the return rate of market in week $t$ and $I_{i, t}$ stands for the return rate of industry in which stock $i$ belongs. The $R^{2}$ value after regression measures the part of stock $i$ 's return that can be explained by systematic pricing factors. The smaller $R^{2}$ reflects higher proportion of the part that cannot be predicted by systematic risks, thus increasing the valuation difficulty.

The fourth indicator is illiquidity index. The Amihud illiquidity ratio [64] is significantly and positively correlated with the information uncertainty of a stock [65]. The formula used to calculate the Amihud illiquidity of stock $i$ in period $t$ is as follows:

$$
\text { Illiquidity }_{i, t}=\frac{1}{n_{i, t}} \sum_{d=1}^{n_{i, t}} \frac{\left|R_{i, t, d}\right|}{V_{i, t, d}}
$$

where $n_{i, t}$ represents the trading days of stock $i$ in period $t$, $R_{i, t, d}$ represents the return rate of stock $i$ on day $d$, and $V_{i, t, d}$ stands for the trading volume of stock $i$ on day $d$ (in units of billion yuan). High illiquidity means high degree of information asymmetry, which makes a stock hard to be analyzed.

We sort all stocks according to the ascending order of stock price volatility, stock characteristic volatility, and illiquidity index and the descending order of $R^{2}$. The ranking of each stock obtained after sorting is divided by the number of stocks to obtain a stock's hard-to-value score at the four dimensions. By adding up the four hard-to-value scores, we can get the score of stock. Taking the proportion of a stock's market value in a mutual fund's investment portfolio as the weight, the valuation difficulty of the fund's portfolio caused by market information uncertainty (HTV_mrkt) is the weighted average of all stocks' scores it holds. 
5.6. Hard-to-Value Portfolio Caused by Fundamental Information Uncertainty. We use seven indicators to measure the hard-to-value portfolio caused by fundamental information uncertainty. The first indicator is the stock size. Small-sized stocks have high information asymmetry and are easier to be affected by market sentiment, increasing their valuation difficulty [66]. We measure stock size as the market value. The second indicator is the proportion of fixed assets to the total asset. According to Baker [34], the tangibility of a company's assets will affect the difficulty of its valuation. The higher the proportion of intangible assets in a company, the more difficult it is to measure its value. Besides, if a company spends more on research and development activities, it is harder to estimate the expected consequences, causing more valuation uncertainty. To this end, the proportion of fixed assets to the total asset has a negative relationship with a stock's valuation difficulty. The third indicator is the volatility of operating income, which is measured as the standard deviation of a stock's operating income in the previous eight quarters. High volatility of operating income increases the valuation difficulty of a stock.

The fourth indicator is the book-to-market ratio. According to Baker [34] and Kumar [33], a lower book-tomarket ratio means higher potential growth of a stock and may increase the valuation difficulty. The fifth and sixth indicators are ROA volatility and ROE volatility, which are measured as the standard deviation of a stock's ROA and ROE for the previous eight quarters, respectively. High volatility of ROA and ROE means low profitability stability, bringing difficulties in valuing a stock.

The seventh and eighth indicators are the share proportion of the largest shareholder and the share proportion of the second to the tenth largest shareholder. La Porta et al. [67] indicate that over dispersed equity is likely to cause serious agency problems and may increase the degree of information asymmetry of a company, thus increasing its difficulty of valuation. The lower the share proportion of the largest shareholder is and the higher the share proportion of the second to the tenth largest shareholder, the more difficult it is to assess a stock's value.

We sort all stocks according to the descending order of stock size, proportion of fixed assets to total asset, book-tomarket ratio, and share proportion of the largest shareholder and the ascending order of the volatility of operating income, ROE, ROA and share proportion of the second to the tenth largest shareholder. The ranking of each indicator obtained after sorting is summed and divided by the number of stocks to obtain a stock's hard-to-value score. We measure the valuation difficulty of a mutual fund's portfolio caused by fundamental information uncertainty $\left(H T V_{-} f d m t\right)$ as the weighted average of all stocks' hard-to-value scores it holds.

5.7. Hard-to-Value Portfolio Caused by Limited Public Information. Two indicators are used to measure the hardto-value portfolio caused by limited public information. The first indicator is the number of analysts who follow a stock in the previous year. Lang and Lundholm [68], Hong et al. [69], and Gleason and Lee [70] all believed that more analysts following a stock will increase its information disclosure and reduce the information asymmetry, which is helpful for reducing the valuation difficulty of the stock.

The second indicator is the size of a stock's accounting firm. Audit reports issued by larger accounting firms usually have higher quality, which can reduce the difficulty of stock valuation. We measure the size of an accounting firm as its annual revenue.

All stocks are sorted according to the descending order of the number of analysts and the size of accounting firm. We then use the methods mentioned above to calculate the hard-to-value score of a mutual fund's hard-to-value score at the public information disclosure aspect (HTV_info).

5.8. Control Variables. We include two sets of control variables related to fund manager and mutual fund that might affect the performance of mutual funds. According to Simutin [71] and Niessen and Ruenzi [72], fund manager's education $(P h D)$ and gender (Gender), tenure length (Tenure), and fund management team size (Teamsize) are controlled at the fund manager aspect. $P h D$ is a dummy variable. If at least one fund manager of a mutual fund holds a $\mathrm{PhD}$ in the current fund management team, the value is 1 ; otherwise, it is 0 . Gender is also a dummy variable. If at least one fund manager in the current fund management team is female, Gender equals to 1 ; otherwise, it equals to 0 . We measure Tenure as the natural logarithm of the average tenure (in units of month) of all managers who manage a mutual fund in the current period. Teamsize is measured as the number of fund managers who jointly manage a mutual fund in the current period.

Following the literature [73-75], we control for factors related to mutual fund characteristics, including fund size (Netasset), fund family size (Familysize), fund age (Fundage), fund's expense ratio (Expense), turnover ratio (Turnover), historical performance (Return), fund flow (Fundflow), and investment style fixed effect (Style). Netasset is equal to the natural logarithm of the total net assets of a mutual fund at the end of the previous period. We measure Familysize as the natural logarithm of the total net assets of the fund family to which a mutual fund belongs at the end of the previous period. Fundage is equal to the natural logarithm of the interval (in units of month) from the founding date of a mutual fund to the end of the previous period. The ratio of the total operating expenses of a mutual fund for the previous period to the average total net assets of the fund at the beginning and ending of the previous period is adopted to measure Expense. Return is measured as the return on equity of the last period of a mutual fund. We use the net capital inflow (in units of billion yuan) in the previous period of a mutual fund to measure Fundflow.

We include a series of dummy variables to control the investment style fixed effect of a mutual fund. Referring to Daniel et al. [76], Pareek [12], and Hoberg et al. [77], the paper describes the investment style of a mutual fund through three dimensions of the stocks in its portfolio: size, book-to-market ratio, and momentum. The current market value (in units of billion yuan) is used to represent the size of 
a stock, and the cumulative return rate in the previous year (excluding the last month to avoid the effect of short-term reversal of price) is used to represent the momentum of a stock. In order to avoid the interference of outliers, the above three indicators are all winsorized by $1 \%$. There are four steps to further construct the dummy variables of investment style. First, we take the natural logarithm of the three dimensions of a stock and then standardize them to get the transformations of size (zlnSize), book-to-market ratio $(z \ln B M)$, and momentum $(z \ln M o m)$. Second, cross-sectional regressions are made for all stocks in each period to obtain a series of regression coefficients:

$$
\begin{aligned}
z \ln B M_{i} & =\alpha+\beta z \ln \text { Size }_{i}+\varepsilon \\
z \ln \text { Mom }_{i} & =\delta+\theta z \ln \text { Size }_{i}+\gamma z \ln B M_{i}+\varepsilon .
\end{aligned}
$$

The book-to-market ratio and momentum after orthogonalization adjustment are

$$
\begin{aligned}
r z \ln B M_{i} & =z \ln B M_{i}-\alpha-\beta z \ln \text { Size }_{i}, \\
r z \ln \mathrm{Mom}_{i} & =z \ln \mathrm{Mom}_{i}-\delta-\theta z \ln \mathrm{Size}_{i}-\gamma z \ln B M_{i} .
\end{aligned}
$$

Third, taking the proportion of a stock's market value in a mutual fund's investment portfolio as the weight, the three indicators of the fund's investment style (i.e., fSize, $f B M$, and $f M o m)$ are the weighted average of all stocks' $\ln S i z e, r z \ln B M$, and $r z \ln M o m$. Fourth, all funds are assigned with the three style scores. Each style score is a scale of 1 to 5 to indicate the ranking of the corresponding indicator in the top 20\%, lower than $20 \%$ but higher than $40 \%$, lower than $40 \%$ but higher than $60 \%$, lower than $60 \%$ but higher than $80 \%$, or last $20 \%$. The combinations of the three style scores generate 125 types of investment styles, and 125 style dummy variables are defined. For example, if a fund ranks $20-40 \%$ in fSize, top $20 \%$ in $f B M$, and last $20 \%$ in $f M o m$, its investment style can be described as " $2-1-5$ " and the corresponding dummy variable equals to 1 .

A series of observation quarter dummies are also used to control for time fixed effect (Quarter), which allows us to reduce the unobservable effects of time.

5.9. Statistical Summaries. Table 1 reports the descriptive statistics and correlation matrix for the key variables. For clarity and the convenience of interpretation, we use the raw values of Netasset, Familysize, Fundage, and Tenure instead of their natural log transformations in Table 1. On average, a mutual fund has 1.73 billion net assets, belongs to a fund family with 44.10 billion net assets, and obtains a $0.44 \%$ adjusted monthly excess return rate. The average fund age is 57.30 months and the average tenure of the fund manager is 26.39 months. $15.9 \%$ of mutual funds have managers with Ph.D. and $22.33 \%$ have a female manager. On average, a mutual fund has 1.39 fund managers, a $2.69 \%$ expense ratio, and a $195.7 \%$ turnover rate.

According to the correlation matrix, apart from the significant correlation between Closeness, Betweenness, and Eigenvector, there is no obvious collinearity between variables. In fact, we do not put the three centrality indicators in one model. The relatively high correlation between the three network centrality is not difficult to understand. The three centrality indicators measure the importance of a node relative to other nodes from different aspects, and the different information advantages driven by the different types of influential positions may convert mutually to some extent $[62,78]$. For example, a node with good relations with nodes having important information positions (i.e., high eigenvector centrality), may construct highly efficient channels to access more information sources (i.e., high closeness centrality) with the help of the influential nodes, and may become information broker of the network information flow (i.e., high betweenness centrality). However, this paper focuses on the different natures of the three centrality indicators, and the following empirical results indicate their differences even if there are high correlations between them.

\section{Fund Network Centrality and Investment Performance}

6.1. Model Specification. To test the relationship between fund network centrality and investment performance, we employ the following fixed effect model and adjust the $t$ value by clustering the observations by fund code:

$$
\begin{aligned}
\text { Performance }_{j, t}= & \alpha+\beta_{1} \cdot \text { Closeness }_{j, t-1}+\beta_{2} \cdot \text { Netasset }_{j, t-1} \\
& +\beta_{3} \cdot \text { Familysize }_{j, t-1}+\beta_{4} \cdot \text { Funda ge }_{j, t-1} \\
& +\beta_{5} \cdot \text { Expense }_{j, t-1}+\beta_{6} \cdot \text { Turnover }_{j, t-1} \\
& +\beta_{7} \cdot \text { Return }_{j, t-1}+\beta_{8} \cdot \text { Fund flow }_{j, t-1} \\
& +\beta_{9} \cdot \text { PhD }_{j, t}+\beta_{10} \cdot \text { Gender }_{j, t} \\
& +\beta_{11} \cdot \text { Teamsize }_{j, t}+\beta_{12} \cdot \text { Tenure }_{j, t} \\
& +\sum_{i} \lambda_{i} \text { Style }_{i, j, t}+\sum_{k} \gamma_{k} \text { Quarter }_{k, t}+\varepsilon_{j, t},
\end{aligned}
$$

where Performance ${ }_{j, t}$ represents the investment performance of fund $j$ in quarter $t$, Closeness $s_{j, t-1}$ represents the closeness centrality of fund $j$ in quarter $t-1$, which can be replaced by Betweenness $_{j, t-1}$ or Eigenvector ${ }_{j, t-1}$ when the effects of betweenness centrality or eigenvector centrality is tested, Netasset $_{j, t-1}$, Familysize $_{j, t-1}$, Fundage $_{j, t-1}$, Expense $_{j, t-1}$, Turnover $_{j, t-1}$, Return $_{j, t-1}$, and Fundflow ${ }_{j, t-1}$ refer to fund $j$ 's net asset, total net asset of its family fund, fund age, expense ratio, turnover ratio, historical performance, and net capital inflow in quarter $t-1, P h D_{j, t}$, Gender $_{j, t}$, Teamsize $_{j, t}$, and Tenure $_{j, t}$ refer to fund managers' education, gender, number of people, and tenure of fund $j$ in quarter $t$, Style $e_{j, t}$ refers to the investment style fixed effect of fund $j$ in quarter $t$, Quarter $_{t}$ refers to the time fixed effect of quarter $t$, and $\varepsilon_{i, t}$ denotes the error term.

6.2. Results. The regression results are shown in Table 2. Model (1-1) shows that the effect of Closeness on Performance is positively significant $(\beta>0 ; p<0.05)$, indicating that mutual funds with high closeness centrality will achieve 


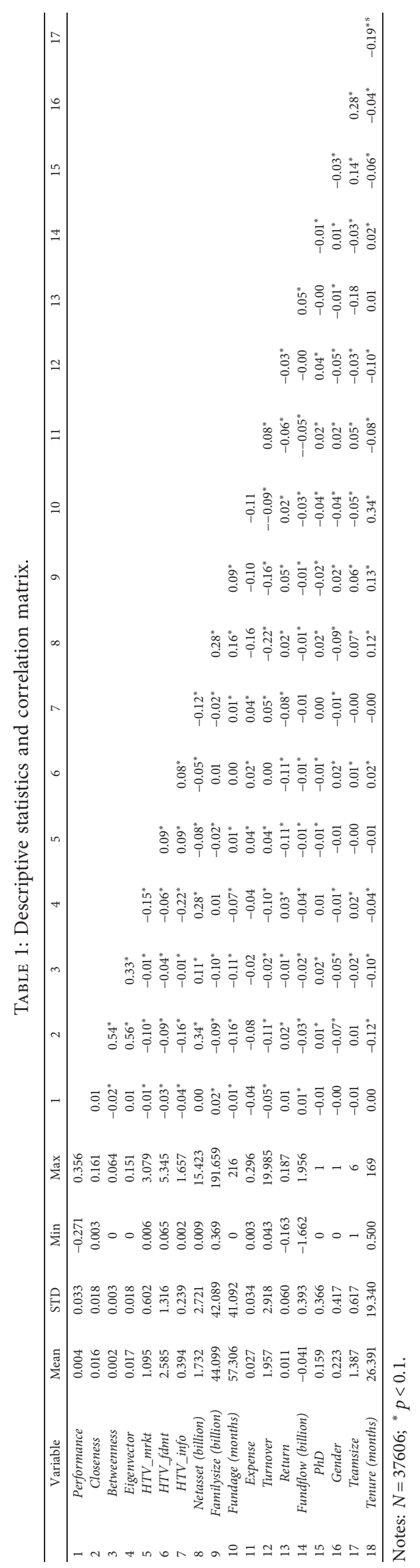


better investment performance. A mutual fund with higher closeness centrality can connect with other entities through shorter information transmission paths, which can increase its efficiency in obtaining public and private information from the fund network [38]. Therefore, high closeness centrality can enhance the breadth of information acquired by a mutual fund, thus improving its investment performance.

Model (1-3) shows that the effect of Eigenvector on Performance is positively significant $(\beta>0 ; p<0.1)$, indicating that mutual funds with high eigenvector centrality will obtain better investment performance. The higher the eigenvector centrality of a mutual fund is, the more information it can get from other entities having important information positions [79, 80]. Information from key information entities usually has high quality and high timeliness and sometimes includes potential private information. As a result, a mutual fund with higher eigenvector centrality has more information depth, which is helpful to improve investment performance.

The coefficient of Betweenness is not significant at the $10 \%$ confidence level in Model (1-2), indicating that betweenness centrality cannot explain for fund performance. The betweenness centrality reflects the mediating effect of a mutual fund on the potential information flow in the fund network [21], rather than the capabilities of using the network location to obtain information. Mutual funds are not financial intermediaries such as investment banks, so betweenness centrality may not give them the information advantages that can be used to improve investment performance.

In conclusion, the above results, to some extent, support Hypothesis 1 that more central position in the fund network help a mutual fund achieve better investment performance, but the effects of closeness centrality, betweenness centrality, and eigenvector centrality are different. The results also show that shorter fund age, larger fund size and fund family size, higher turnover rate, and longer tenure of the present fund managers may cause worse fund performance.

\section{Hard-to-Value Portfolio and Investment Performance}

7.1. Model Specification. The fixed effect model used to test the relationships between hard-to-value portfolio and investment performance is set as follows:

$$
\begin{aligned}
\text { Performance }_{j, t}= & \alpha+\beta \cdot H T V_{-} \text {mrkt }_{j, t}+\sum_{i} \lambda_{i} \text { Control }_{i j, t-1} \\
& +\varepsilon_{j, t},
\end{aligned}
$$

where Performance ${ }_{j, t}$ represents the investment performance of fund $j$ in quarter $t$ and $H T V \_m r k t_{j, t}$ represents the hardto-value portfolio caused by market information uncertainty of fund $j$ 's in quarter $t$, which can be replaced by $H T V_{-} f d m t_{j, t}$ or HTV_info $o_{j, t}$ when the return of hard-to-value portfolio caused by fundamental information uncertainty or limited
TABLE 2: The effect of fund network centrality on investment

\begin{tabular}{|c|c|c|c|}
\hline & \multicolumn{3}{|c|}{ Performance } \\
\hline & $(1-1)$ & $(1-2)$ & $(1-3)$ \\
\hline Closeness & $\begin{array}{c}12.783^{* *} \\
(5.985)\end{array}$ & & \\
\hline Betweenness & & $\begin{array}{c}5.500 \\
(5.491)\end{array}$ & \\
\hline Eigenvector & & & $\begin{array}{l}2.059^{*} \\
(1.136)\end{array}$ \\
\hline Netasset & $\begin{array}{c}-0.139^{* * *} \\
(0.029)\end{array}$ & $\begin{array}{c}-0.136^{* * *} \\
(0.029)\end{array}$ & $\begin{array}{c}-0.139^{* * *} \\
(0.030)\end{array}$ \\
\hline Familysize & $\begin{array}{c}-0.146^{* *} \\
(0.063)\end{array}$ & $\begin{array}{c}-0.145^{* *} \\
(0.063)\end{array}$ & $\begin{array}{c}-0.146^{* *} \\
(0.063)\end{array}$ \\
\hline Fundage & $\begin{array}{c}0.353^{* * * *} \\
(0.067)\end{array}$ & $\begin{array}{c}0.356^{* * * *} \\
(0.067)\end{array}$ & $\begin{array}{c}0.352^{* * *} \\
(0.067)\end{array}$ \\
\hline Expense & $\begin{array}{c}1.900 \\
(1.223)\end{array}$ & $\begin{array}{c}1.939 \\
(1.224)\end{array}$ & $\begin{array}{c}1.880 \\
(1.222)\end{array}$ \\
\hline Turnover & $\begin{array}{c}-0.106^{* * *} \\
(0.015)\end{array}$ & $\begin{array}{c}-0.106^{* * *} \\
(0.015)\end{array}$ & $\begin{array}{c}-0.105^{* * *} \\
(0.015)\end{array}$ \\
\hline Return & $\begin{array}{l}-0.007 \\
(0.006)\end{array}$ & $\begin{array}{l}-0.006 \\
(0.006)\end{array}$ & $\begin{array}{l}-0.007 \\
(0.006)\end{array}$ \\
\hline Fundflow & $\begin{array}{c}0.068 \\
(0.042)\end{array}$ & $\begin{array}{c}0.067 \\
(0.042)\end{array}$ & $\begin{array}{c}0.068 \\
(0.042)\end{array}$ \\
\hline$P h D$ & $\begin{array}{c}0.059 \\
(0.065)\end{array}$ & $\begin{array}{c}0.057 \\
(0.065)\end{array}$ & $\begin{array}{c}0.058 \\
(0.065)\end{array}$ \\
\hline Gender & $\begin{array}{c}0.003 \\
(0.066)\end{array}$ & $\begin{array}{c}0.003 \\
(0.066)\end{array}$ & $\begin{array}{c}0.003 \\
(0.066)\end{array}$ \\
\hline Teamsize & $\begin{array}{l}-0.054 \\
(0.038)\end{array}$ & $\begin{array}{l}-0.052 \\
(0.038)\end{array}$ & $\begin{array}{l}-0.053 \\
(0.038)\end{array}$ \\
\hline Tenure & $\begin{array}{c}-0.083^{* * *} \\
(0.027)\end{array}$ & $\begin{array}{c}-0.083^{* * *} \\
(0.027)\end{array}$ & $\begin{array}{c}-0.083^{* * *} \\
(0.027)\end{array}$ \\
\hline Time fixed effect & Included & Included & Included \\
\hline Style fixed effect & Included & Included & Included \\
\hline Constant & $\begin{array}{c}4.517^{* * *} \\
(1.512)\end{array}$ & $\begin{array}{c}6.026^{* * *} \\
(1.373)\end{array}$ & $\begin{array}{c}6.060^{* * *} \\
(1.366)\end{array}$ \\
\hline Cluster & Fund & Fund & Fund \\
\hline Observation & 37607 & 37607 & 37607 \\
\hline$R^{2}$ (within) & 0.211 & 0.211 & 0.211 \\
\hline
\end{tabular}
performance.

Notes: standard errors in parentheses; ${ }^{*} p<0.1, * * p<0.05$, and $* * * p<0.01$.

public information is tested. The other control variables of equation (11) are those that included in equation (10). $\varepsilon_{i, t}$ denotes the error term.

7.2. Results. The regression results are shown in Table 3. Models (2-1) and (2-2) show that the parameter estimate for HTV_mrkt and HTV_fdmt are both positive $(\beta>0)$ and are significant at the $1 \%$ level and the $5 \%$ level, respectively. According to the results, mutual funds holding hard-tovalue portfolios caused by market or fundamental information uncertainty will achieve better investment performance. Guo et al. [37] points out that the market or fundamental information uncertainty can lead to asset mispricing [81]. To this end, mutual funds have some capabilities of information mining and analysis to deal with that uncertain information, thus taking use of the mispricing of hard-to-value stocks in their portfolios to improve investment performance. 
TABLE 3: The effect of hard-to-value portfolio on investment performance.

\begin{tabular}{|c|c|c|c|}
\hline & & Performance & \\
\hline & $(2-1)$ & $(2-2)$ & $(2-3)$ \\
\hline$H T V \_m r k t$ & $\begin{array}{c}0.236^{* * *} \\
(0.047)\end{array}$ & & \\
\hline$H T V_{-} f d m t$ & & $\begin{array}{c}0.046^{* *} \\
(0.021)\end{array}$ & \\
\hline$H T V \_i n f o$ & & & $\begin{array}{c}-0.175^{*} \\
(0.110)\end{array}$ \\
\hline Netasset & $\begin{array}{c}-0.135^{* * *} \\
(0.029)\end{array}$ & $\begin{array}{c}-0.137^{* * *} \\
(0.029)\end{array}$ & $\begin{array}{c}-0.138^{* * *} \\
(0.029)\end{array}$ \\
\hline Familysize & $\begin{array}{c}-0.146^{* *} \\
(0.063)\end{array}$ & $\begin{array}{c}-0.147^{* *} \\
(0.063)\end{array}$ & $\begin{array}{c}-0.146^{* *} \\
(0.063)\end{array}$ \\
\hline Fundage & $\begin{array}{c}0.357^{* * *} \\
(0.067)\end{array}$ & $\begin{array}{c}0.355^{* * *} \\
(0.067)\end{array}$ & $\begin{array}{c}0.353^{* * *} \\
(0.067)\end{array}$ \\
\hline Expense & $\begin{array}{c}1.967 \\
(1.223)\end{array}$ & $\begin{array}{c}1.932 \\
(1.223)\end{array}$ & $\begin{array}{c}1.897 \\
(1.222)\end{array}$ \\
\hline Turnover & $\begin{array}{c}-0.107^{* * *} \\
(0.015)\end{array}$ & $\begin{array}{c}-0.106^{* * *} \\
(0.015)\end{array}$ & $\begin{array}{c}-0.105^{* * *} \\
(0.015)\end{array}$ \\
\hline Return & $\begin{array}{l}-0.006 \\
(0.006)\end{array}$ & $\begin{array}{l}-0.006 \\
(0.006)\end{array}$ & $\begin{array}{l}-0.007 \\
(0.006)\end{array}$ \\
\hline Fundflow & $\begin{array}{c}0.069 \\
(0.042)\end{array}$ & $\begin{array}{c}0.068 \\
(0.042)\end{array}$ & $\begin{array}{c}0.067 \\
(0.042)\end{array}$ \\
\hline$P h D$ & $\begin{array}{c}0.059 \\
(0.065)\end{array}$ & $\begin{array}{c}0.059 \\
(0.065)\end{array}$ & $\begin{array}{c}0.058 \\
(0.065)\end{array}$ \\
\hline Gender & $\begin{array}{c}0.009 \\
(0.066)\end{array}$ & $\begin{array}{c}0.005 \\
(0.066)\end{array}$ & $\begin{array}{l}<0.001 \\
(0.067)\end{array}$ \\
\hline Teamsize & $\begin{array}{l}-0.052 \\
(0.038)\end{array}$ & $\begin{array}{l}-0.052 \\
(0.038)\end{array}$ & $\begin{array}{l}-0.052 \\
(0.038)\end{array}$ \\
\hline Tenure & $\begin{array}{c}-0.085^{* * *} \\
(0.027)\end{array}$ & $\begin{array}{c}-0.084^{* * * *} \\
(0.027)\end{array}$ & $\begin{array}{c}-0.081^{* * *} \\
(0.027)\end{array}$ \\
\hline Time fixed effect & Included & Included & Included \\
\hline Style fixed effect & Included & Included & Included \\
\hline Constant & $\begin{array}{c}5.908^{* * *} \\
(1.365)\end{array}$ & $\begin{array}{c}6.119^{* * *} \\
(1.366)\end{array}$ & $\begin{array}{c}6.230^{* * *} \\
(1.370)\end{array}$ \\
\hline Cluster & Fund & Fund & Fund \\
\hline Observation & 37607 & 37607 & 37607 \\
\hline R2(within) & 0.211 & 0.211 & 0.211 \\
\hline
\end{tabular}

Notes: standard errors in parentheses; ${ }^{*} p<0.1,{ }^{* *} p<0.05$, and ${ }^{* * *} p<0.01$.

Model (2-3) shows that effect of HTV_info on Performance is significantly negative $(\beta<0 ; p<0.1)$, indicating that holding hard-to-value portfolio caused by limited public information will make fund performance worse. Poor disclosure of public information negatively affects the investment research of mutual funds [27]. Although information capabilities of mutual funds can help them deal with information uncertainty from market and company fundamentals, they may become helpless when the public information that can be used in investment decision is limited. That is why mutual funds holding hard-to-value portfolios shaped by poor disclosure of public information may lead to bad investment performance.

To sum up, although the empirical results do not fully support Hypothesis 2 because holding a hard-to-value portfolio caused by limited public information has negative influences on fund performance, they indicate that there are different returns between hard-to-value portfolios caused by the market or fundamental information uncertainty and hard-to-value portfolios caused by limited public information.

\section{Fund Network Centrality and Return of Hard-to-Value Stock Portfolio}

8.1. Model Specification. To test the impacts of fund network centrality on mutual fund's return from hard-to-value portfolio, the fixed effect model is used as follows:

$$
\begin{aligned}
\text { Performance }_{j, t}= & \alpha+\beta_{1} \cdot \text { Closeness }_{j, t-1}+\beta_{2} \cdot H T V \_m r k t_{j, t} \\
& +\beta_{3} \cdot \text { Closeness }_{j, t-1} \cdot H T V \_m r k t_{j, t} \\
& +\sum_{i} \lambda_{i} \text { Control }_{i j, t-1}+\varepsilon_{j, t},
\end{aligned}
$$

where Performance ${ }_{j, t}$ represents the investment performance of fund $j$ in quarter $t$, Closeness $s_{j, t-1}$ represents the closeness centrality of fund $j$ in quarter $t-1$, and $H T V_{-} m r k t_{j, t}$ represents the hard-to-value portfolio caused by market information uncertainty of fund $j$ in quarter $t$. The interaction term Closeness $s_{j, t-1} \times H T V \_m r k t_{j, t}$ is included to examine the impact of closeness centrality on the return of hard-to-value portfolio caused by market information uncertainty. In order to capture the effects of the three network centrality indicators on the returns of the three types of hard-to-value portfolio, Closeness $s_{j, t-1}$ can be replaced by Betweenness $j_{j, t-1}$ or Eigenvector $_{j, t-1}$ and $H T V_{-} m r k t_{j, t}$ can be replaced by $H T V_{-} f d m t_{j, t}$ or $H T V_{-} i n f o_{j, t}$. To avoid multicollinearity, any two variables used to construct interaction terms are standardized before their multiplication. The other control variables of (12) are those that are included in equation (10). $\varepsilon_{i, t}$ denotes the error term.

8.2. Results. The regression results are shown in Table 4 . Models (3-4) to (3-6) show that all interaction terms between Betweenness and HTV_mrkt, HTV_fdmt, or HTV_info are not significant at the $10 \%$ confidence level. These results further indicate that betweenness centrality cannot provide a mutual fund with information advantage that can be used in investment activities, making it unable to help the mutual fund profit from its hard-to-value portfolios.

Model (3-3) shows that the coefficient of Closeness $\times H T V \_$info is significantly positive $(\beta>0 ; p<0.1)$, indicating that mutual funds with high closeness centrality are more likely to avoid loss from holding hard-to-value portfolios caused by limited public information. High closeness centrality can improve the breadth of the information acquired by a mutual fund and enable the fund to access to richer information sources [41]. Therefore, mutual funds with high closeness centrality can break through the limitations of poor disclosure of public information. The coefficient of Eigenvector $\times H T V$ info is significantly positive in Model (3-9) as well $(\beta>0 ; p<0.01)$, indicating that eigenvector centrality can also reduce the negative impacts of holding hard-to-value portfolios caused by limited public information. High eigenvector centrality can improve a mutual fund's depth of information acquisition, especially 


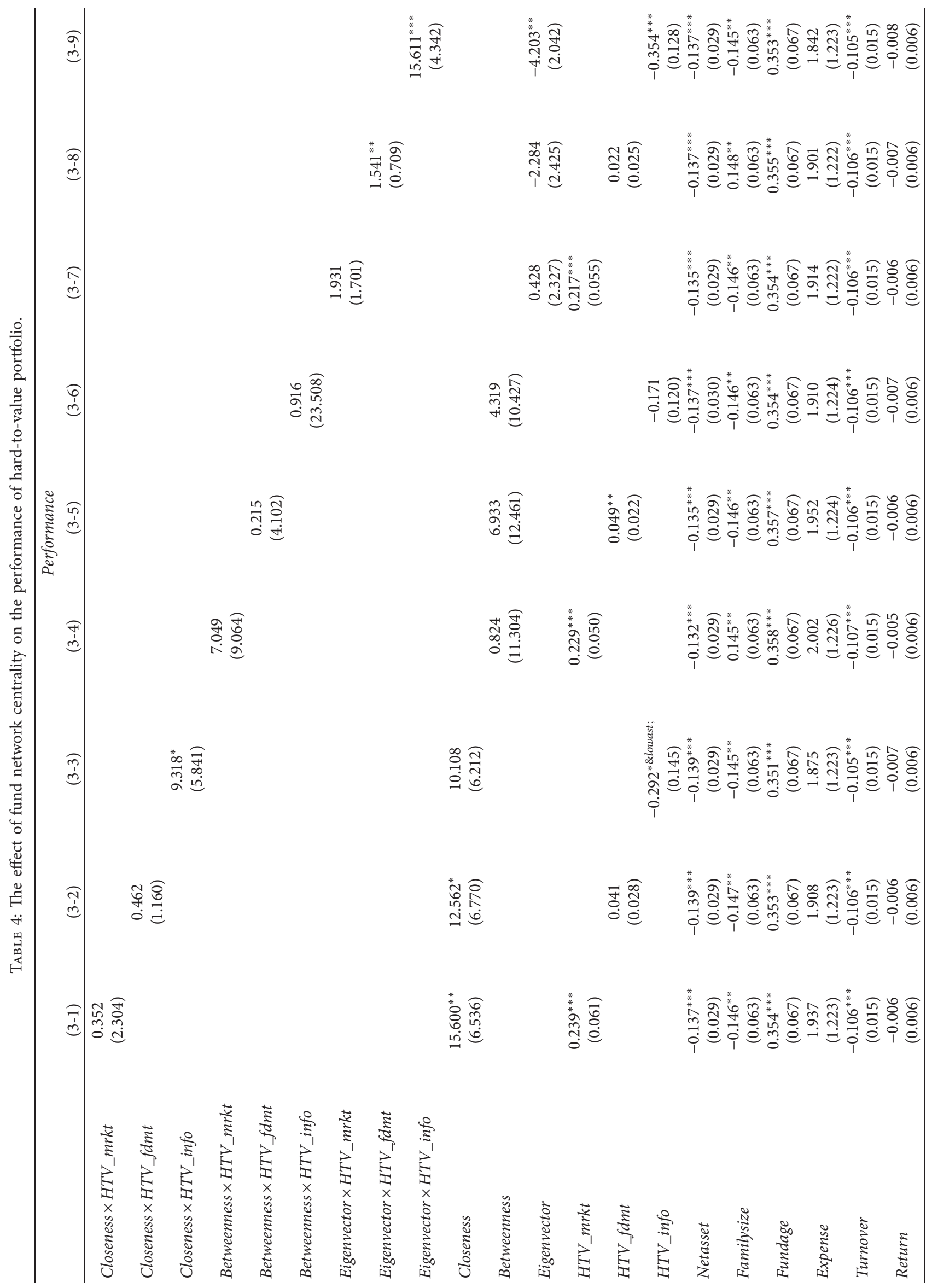




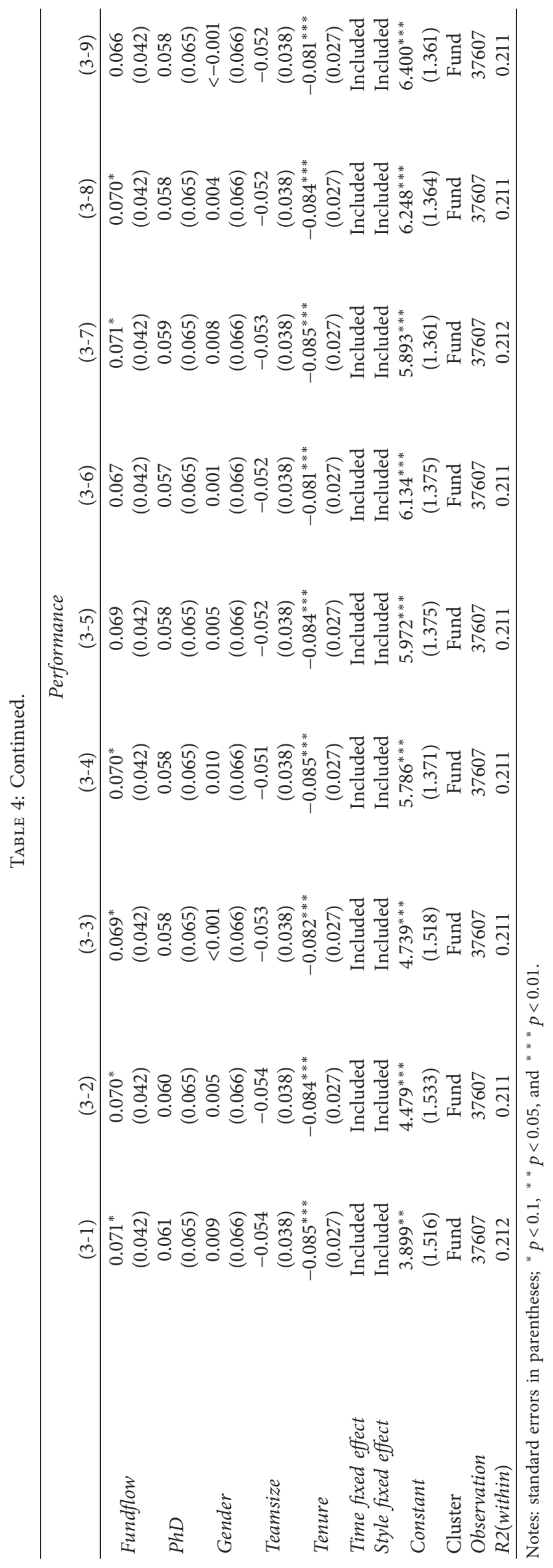


helping the mutual fund obtain potential private information from other entities having important information positions. More private information can supplement the lack of public information when the mutual fund analyzes hard-tovalue assets caused by limited public information.

In Model (3-8), the coefficient of Eigenvector $\times H T V_{-} f d m t$ is significantly positive $(\beta>0$; $p<0.05)$, while the coefficient of Closeness $\times H T V \_f d m t$ is not significant at the $10 \%$ confidence level. The results indicate that the advantages of fundamental information rely more on the information depth than the information breadth. More specifically, high-quality information from entities having important information positions (i.e., high eigenvector centrality) can help mutual funds gain returns from hard-to-value portfolios caused by fundamental information uncertainty, while obtaining public and private information through high-efficiency information transmission path (i.e., high closeness centrality) contributes little to the performance of this type of hard-to-value portfolio.

The coefficients of Closeness $\times$ HTV_mrkt and Eigenvector $\times H T V \_m r k t$ both are not significant at the $10 \%$ confidence level. The results indicate that high closeness centrality or high eigenvector centrality cannot help mutual funds achieve better performance from holding hard-tovalue portfolios caused by market information uncertainty. In other words, it is quite difficult for a mutual fund to use its information breadth and depth brought by the fund network to deal with the information uncertainty at the market level. The possible reason may be that information about stock price spread more easily than information about company fundamental, so the information exchanges in the fund network are more likely to make mutual funds have similar market information rather than fundamental information. Consequently, homogeneous market information cannot guarantee a mutual fund to obtain enough market information advantages relative to others by using its network position, thus preventing it to profit from its hard-to-value portfolios caused by market information uncertainty.

In summary, the results support Hypothesis 3 to some extent, indicating that the information breadth brought by closeness centrality have positive influences on the returns of hard-to-value portfolios caused by limited public information, and the information depth brought by eigenvector centrality have positive influences both on the returns of hard-to-value portfolios caused by limited public information or fundamental information uncertainty.

\section{Conclusions}

Using the quarterly data of China's mutual funds from the fourth quarter of 2004 to the fourth quarter of 2019, this paper constructs a series of complex bipartite networks based on the overlapped portfolios of mutual funds and then explores the mechanism by how the position of a mutual fund in the fund network influences its performance. The results show that the information breadth brought by closeness centrality and the information depth brought by eigenvector centrality help a mutual fund achieve better investment performance, but the information intermediation brought by betweenness centrality has no significant influence on investment performance. We also find that holding stock portfolios with high valuation difficulties caused by the market or fundamental information uncertainty will lead to better fund performance, but while holding hard-to-value portfolios caused by limited public information has negative influences on fund performance. Furthermore, closeness centrality and eigenvector centrality can reduce the likelihood of a mutual fund holding hard-tovalue portfolios caused by limited public information to achieve worse performance. Eigenvector centrality positively moderates the relationship between hard-to-value portfolios caused by fundamental information uncertainty and investment performance.

The main contributions of this paper are as follows. First, most of the previous studies use the degree centrality of a one-mode fund network to explore the influences of the fund network position $[12,24,59]$. Based on graph theory, we construct bipartite networks based on the overlapped portfolios of mutual funds and calculate the closeness centrality, betweenness centrality, and eigenvector centrality of mutual funds in the networks, and then reveal the influences of the three centrality indicators on mutual fund's investment behavior and performance. Compared with a one-mode fund network, a bipartite network can comprehensively describe the information channels of mutual funds to access other funds and listed companies. Besides, closeness centrality, betweenness centrality, and eigenvector centrality reflect the overall picture of all direct and indirect relations and capture richer structural features of the fund network compared to degree centrality. At the same time, we further indicate that the three centrality indicators bring different information advantages, so they have different influences on mutual funds. Second, this paper constructs indicators to measure three types of hard-to-value portfolios according to the three causes (i.e., market information uncertainty, fundamental information uncertainty, and limited public information). The three types of hard-to-value portfolios have different information natures, thus bringing different influences on fund performance. Third, this paper examines the effects of closeness centrality, betweenness centrality, and eigenvector centrality on the returns of hardto-value portfolios, respectively. We emphasize that a mutual fund should make appropriate use of the information advantages brought by the fund networks to improve its capabilities of information mining and analysis required for investing in hard-to-value stocks.

There are two main practical implications. First, for the investors of mutual funds, the methods in the paper about constructing the bipartite network based on the overlapped portfolios of mutual funds and calculating the fund network centrality indicators can help them judge the information advantages of each mutual fund. In fact, closeness centrality and eigenvector centrality are two important drives for fund performance. Second, for fund managers, we point out that they need to expand their information breadth by establishing relations with more listed companies and other mutual funds and increase their information depth by connecting with those institutions having important 
information positions. Additionally, fund managers should actively use their information advantages to invest in stocks with high levels of market or fundamental information uncertainty and avoid holding stocks having limited public information.

This paper has some limitations that can also provide promising directions for future research. First, this paper discusses the impacts of fund networks on mutual fund's investment behavior and performance, but only focuses on the analysis of network centrality. However, there are many other important network characteristics, such as network density, tie strength, and network constrain. It would be valuable to conduct more research on how other characteristics of the fund network perform. Second, we explore the influences of the information advantages brought by fund networks on mutual fund behavior of holding hard-to-value portfolios. Other investment behaviors such as diversification and timing choice require more explorations in further studies.

\section{Endnotes}

According to Statman [82], diversified investment in more than 20 stocks can basically eliminate most of the nonsystemic risks. When a mutual fund holds more than $5 \%$ of its all position in a stock, it means that the fund manager is relatively confident in that stock and may own the private information of that stock. Therefore, we set the threshold of a mutual fund's large position as $5 \%$.

\section{Data Availability}

The data used to support the findings of this study are available from the corresponding author upon request

\section{Conflicts of Interest}

The authors declare that they have no conflicts of interest regarding the publication of this paper.

\section{Acknowledgments}

The authors would like to acknowledge the financial support from the National Natural Science Foundation of China (nos. 72002175 and 72002033), Fundamental Research Funds for the Central Universities in UIBE (nos. CXTD1005, CXTD 11-04, and 19YQ08), Foundation for Disciplinary Development of SITM in UIBE, and Fundamental Research Funds for the Central Universities in BFSU (no. 2020JJ006)

\section{References}

[1] R. Wermers, "Mutual fund performance: an empirical decomposition into stock-picking talent, style, transactions costs, and expenses," The Journal of Finance, vol. 55, no. 4, pp. 1655-1695, 2000.

[2] S. Gibson, A. Safieddine, and R. Sonti, "Smart investments by smart money: evidence from seasoned equity offerings," Journal of Financial Economics, vol. 72, no. 3, pp. 581-604, 2004.
[3] M. Baker, L. Litov, J. A. Wachter, and J. Wurgler, "Can mutual fund managers pick stocks? Evidence from their trades prior to earnings announcements," Journal of Financial and Quantitative Analysis, vol. 45, no. 5, pp. 1111-1131, 2010.

[4] M. Kacperczyk, S. V. Nieuwerburgh, and L. Veldkamp, "Time-varying fund manager skill," The Journal of Finance, vol. 69, no. 4, pp. 1455-1484, 2014.

[5] M. Granovetter, "Economic action and social structure: the problem of embeddedness," American Journal of Sociology, vol. 91, no. 3, pp. 481-510, 1985.

[6] J. Y. Zhao, Y. J. Wang, X. Xi, and G. D. Wu, "Simulation of steel production logistics system based on multi-agents," International Journal of Simulation Modelling, vol. 16, no. 1, pp. 167-175, 2017.

[7] B. Andres, R. Poler, L. M. Camarinha-Matos, and H. Afsarmanesh, "A simulation approach to assess partners selected for a collaborative network," International Journal of Simulation Modelling, vol. 16, no. 3, pp. 399-411, 2017.

[8] H. S. Lee and W. S. Lee, "International linkage among mena financial markets," Economic Computation \& Economic Cybernetics Studies \& Research, vol. 53, no. 3, pp. 277-296, 2019.

[9] R. S. Burt, Structural Holes: The Social Structure of Competition, Harvard University Press, Cambridge, MA, USA, 1992.

[10] J. M. Podolny, "Networks as the pipes and prisms of the market," American Journal of Sociology, vol. 107, no. 1, pp. 33-60, 2001.

[11] H. Hong, J. D. Kubik, and J. C. Stein, "Thy neighbor's portfolio: word-of-mouth effects in the holdings and trades of money managers," The Journal of Finance, vol. 60, no. 6, pp. 2801-2824, 2005.

[12] A. Pareek, "Information networks: implications for mutual fund trading behavior and stock returns," in in Proceedings of the AFA 2010 Atlanta Meetings Paper, Atlanta, GA, USA, January 2012.

[13] V. K. Pool, N. Stoffman, and S. E. Yonker, "The people in your neighborhood: social interactions and mutual fund portfolios," The Journal of Finance, vol. 70, no. 6, pp. 2679-2732, 2015.

[14] B. J. Bushee and T. H. Goodman, "Which institutional investors trade based on private information about earnings and returns?" Journal of Accounting Research, vol. 45, no. 2, pp. 289-321, 2007.

[15] H. Jiang, "Institutional investors, intangible information, and the book-to-market effect," Journal of Financial Economics, vol. 96, no. 1, pp. 98-126, 2010.

[16] S. S. Crawford, W. R. Gray, and A. E. Kern, "Why do fund managers identify and share profitable ideas?" Journal of Financial and Quantitative Analysis, vol. 52, no. 5, pp. 1903-1926, 2017.

[17] J. L. Iribarren and E. Moro, "Affinity paths and information diffusion in social networks," Social Networks, vol. 33, no. 2, pp. 134-142, 2011.

[18] P.-H. Soh and E. B. Roberts, "Technology alliances and networks: an external link to research capability," IEEE Transactions on Engineering Management, vol. 52, no. 4, pp. 419-428, 2005.

[19] M. A. Carpenter, M. Li, and H. Jiang, "Social network research in organizational contexts," Journal of Management, vol. 38, no. 4, pp. 1328-1361, 2012.

[20] G. Sabidussi, “The centrality index of a graph," Psychometrika, vol. 31, no. 4, pp. 581-603, 1966.

[21] L. C. Freeman, D. Roeder, and R. R. Mulholland, "Centrality in social networks: ii. experimental results," Social Networks, vol. 2, no. 2, pp. 119-141, 1979. 
[22] N. E. Friedkin, "Theoretical foundations for centrality measures," American Journal of Sociology, vol. 96, no. 6, pp. 1478-1504, 1991.

[23] Z. L. Tian, R. H. Liu, and Y. Liu, "Information transmission, collective stampede and systematic tail risk," China Economic Quarterly, vol. 18, no. 3, pp. 897-918, 2019, in Chinese.

[24] R. H. Luo and Z. L. Tian, "Mutual fund network, competition barrier and stock information environment," China Industrial Economics, vol. 3, pp. 137-154, 2020, in Chinese.

[25] Y. Shen, J. M. Zhao, and X. He, "Alumni network, funds' performance and 'Small world' effect," China Economic Quarterly, vol. 15, no. 1, pp. 403-428, 2016, in Chinese.

[26] J. Wurgler and E. Zhuravskaya, "Does arbitrage flatten demand curves for stocks?" The Journal of Business, vol. 75, no. 4, pp. 583-608, 2002.

[27] B. Cornell, W. R. Landsman, and S. R. Stubben, "Accounting information, investor sentiment, and market pricing," Journal of Law, Finance, and Accounting, vol. 2, no. 2, pp. 325-345, 2017.

[28] K. Chan and A. Hameed, "Stock price synchronicity and analyst coverage in emerging markets," Journal of Financial Economics, vol. 80, no. 1, pp. 115-147, 2006.

[29] K. Daniel, D. Hirshleifer, and A. Subrahmanyam, "Investor psychology and security market under- and overreactions," The Journal of Finance, vol. 53, no. 6, pp. 1839-1885, 1998.

[30] K. D. Daniel, D. Hirshleifer, and A. Subrahmanyam, "Overconfidence, arbitrage, and equilibrium asset pricing," The Journal of Finance, vol. 56, no. 3, pp. 921-965, 2001.

[31] D. Hirshleifer, "Investor psychology and asset pricing," The Journal of Finance, vol. 56, no. 4, pp. 1533-1597, 2001.

[32] B. M. Barber, T. Odean, and N. Zhu, "Do retail trades move markets?" Review of Financial Studies, vol. 22, no. 1, pp. 151-186, 2009.

[33] A. Kumar, "Hard-to-value stocks, behavioral biases, and informed trading," Journal of Financial and Quantitative Analysis, vol. 44, no. 6, pp. 1375-1401, 2009.

[34] M. Baker and J. Wurgler, "Investor sentiment and the crosssection of stock returns," The Journal of Finance, vol. 61, no. 4, pp. 1645-1680, 2006.

[35] M. Baker and J. Wurgler, "Investor sentiment in the stock market," Journal of Economic Perspectives, vol. 21, no. 2, pp. 129-151, 2007.

[36] S. Lai, L. Ng, and B. Zhang, "Does PIN affect equity prices around the world?" Journal of Financial Economics, vol. 114, no. 1, pp. 178-195, 2014.

[37] Q. Y. Guo, R. H. Luo, and Y. Liu, "Difficulty in stock analysis and mutual fund's information advantage," Chinese Review of Financial Studies, vol. 9, no. 6, pp. 16-32, 2017, in Chinese.

[38] W. W. Powell, K. W. Koput, and L. Smith-Doerr, "Interorganizational collaboration and the locus of innovation: networks of learning in biotechnology," Administrative Science Quarterly, vol. 41, no. 1, pp. 116-145, 1996.

[39] D. J. Brass and M. E. Burkhardt, "Potential power and power use: an investigation of structure and behavior," Academy of Management Journal, vol. 36, no. 3, pp. 441-470, 1993.

[40] T. J. Rowley, "Moving beyond dyadic ties: a network theory of stakeholder influences," Academy of Management Review, vol. 22, no. 4, pp. 887-910, 1997.

[41] R. Gulati, "Network location and learning: the influence of network resources and firm capabilities on alliance formation," Strategic Management Journal, vol. 20, no. 5, pp. 397-420, 1999.
[42] O. Sorenson and T. E. Stuart, "Syndication networks and the spatial distribution of venture capital investments," American Journal of Sociology, vol. 106, no. 6, pp. 1546-1588, 2001.

[43] P. Hage and F. Harary, "Eccentricity and centrality in networks," Social Networks, vol. 17, no. 1, pp. 57-63, 1995.

[44] L. C. Freeman, "A set of measures of centrality based on betweenness," Sociometry, vol. 40, no. 1, pp. 35-41, 1977.

[45] P. Bonacich, "Factoring and weighting approaches to status scores and clique identification," The Journal of Mathematical Sociology, vol. 2, no. 1, pp. 113-120, 1972.

[46] H.-L. Chen, N. Jegadeesh, and R. Wermers, "The value of active mutual fund management: an examination of the stockholdings and trades of fund managers," The Journal of Financial and Quantitative Analysis, vol. 35, no. 3, pp. 343$368,2000$.

[47] J. P. H. Fan and T. J. Wong, "Corporate ownership structure and the informativeness of accounting earnings in East Asia," Journal of Accounting and Economics, vol. 33, no. 3, pp. 401-425, 2002.

[48] R. Ding, W. Hou, J.-M. Kuo, and E. Lee, "Fund ownership and stock price informativeness of Chinese listed firms," Journal of Multinational Financial Management, vol. 23, no. 3, pp. 166-185, 2013.

[49] D. Liu, H. Gu, and P. Lung, "The equity mispricing: evidence from China's stock market," Pacific-Basin Finance Journal, vol. 39, no. 39, pp. 211-223, 2016.

[50] W. M. Fong, "Speculative trading and stock returns: a stochastic dominance analysis of the Chinese A-share market," Journal of International Financial Markets, Institutions and Money, vol. 19, no. 4, pp. 712-727, 2009.

[51] E. Xiang, G. Y. Tian, F. Yang, and Z. Liu, "Do mutual funds have information advantage? Evidence from seasoned equity offerings in China," International Review of Financial Analysis, vol. 31, pp. 70-79, 2014.

[52] R. B. Cohen, C. Polk, and B. Silli, "Best ideas," London School of Economics, London, UK, 2010.

[53] R. Shiller and J. Pound, "Survey evidence of diffusion of interest among institutional investors," NBER Working Paper 1851, 1986.

[54] B. J. Bushee, M. J. Jung, and G. S. Miller, "Conference presentations and the disclosure milieu," Journal of Accounting Research, vol. 49, no. 5, pp. 1163-1192, 2011.

[55] B. J. Bushee, J. Gerakos, and L. F. Lee, "Corporate jets and private meetings with investors," Journal of Accounting and Economics, vol. 65, no. 2-3, pp. 358-379, 2018.

[56] L. Cohen, A. Frazzini, and C. Malloy, "The small world of investing: board connections and mutual fund returns," Journal of Political Economy, vol. 116, no. 5, pp. 951-979, 2008.

[57] R. Frankel, M. Johnson, and D. J. Skinner, "An empirical examination of conference calls as a voluntary disclosure medium," Journal of Accounting Research, vol. 37, no. 1, pp. 133-150, 1999.

[58] D. Delpini, S. Battiston, G. Caldarelli, and M. Riccaboni, "The network of U.S. mutual fund investments: diversification, similarity and fragility throughout the global financial crisis," 2018, https://arxiv.org/abs/1801.02205.

[59] J. F. Lavin, M. A. Valle, and N. S. Magner, "Modeling overlapped mutual funds' portfolios: a bipartite network spproach," Complexity, vol. 2019, Article ID 1565698, 20 pages, 2019.

[60] V. Agarwal, K. A. Mullally, Y. Tang, and B. Yang, "Mandatory portfolio disclosure, stock liquidity, and mutual fund performance," The Journal of Finance, vol. 70, no. 6, pp. 2733-2776, 2015. 
[61] M. M. Carhart, "On persistence in mutual fund performance," The Journal of Finance, vol. 52, no. 1, pp. 57-82, 1997.

[62] K. Faust, "Centrality in affiliation networks," Social Networks, vol. 19, no. 2, pp. 157-191, 1997.

[63] P. Bonacich, "Communication networks and collective action," Social Networks, vol. 9, no. 4, pp. 389-396, 1987.

[64] Y. Amihud, "Illiquidity and stock returns: cross-section and time-series effects," Journal of Financial Markets, vol. 5, no. 1, pp. 31-56, 2002.

[65] W. Kang, N. Li, and H. Zhang, "Information uncertainty and the pricing of liquidity," Journal of Empirical Finance, vol. 54, pp. 77-96, 2019.

[66] O. A. Lamont and R. H. Thaler, "Can the market add and subtract? Mispricing in tech stock carve-outs," Journal of Political Economy, vol. 111, no. 2, pp. 227-268, 2003.

[67] R. La Porta, F. Lopez-de-Silanes, A. Shleifer, and R. Vishny, "Law and finance," Journal of Political Economy, vol. 106, no. 6, pp. 1113-1155, 1998.

[68] M. H. Lang and R. J. Lundholm, "Corporate disclosure policy and analyst behavior," Accounting Review, vol. 71, no. 4, pp. 467-492, 1996.

[69] H. Hong, T. Lim, and J. C. Stein, "Bad news travels slowly: size, analyst coverage, and the profitability of momentum strategies," The Journal of Finance, vol. 55, no. 1, pp. 265-295, 2000.

[70] C. A. Gleason and C. M. C. Lee, "Analyst forecast revisions and market price discovery," The Accounting Review, vol. 78, no. 1, pp. 193-225, 2003.

[71] M. Simutin, "Standing out in the fund family: deviation from a family portfolio predicts mutual fund performance," University of Toronto, Toronto, Canada, 2013.

[72] A. Niessen-Ruenzi and S. Ruenzi, "Sex matters: gender bias in the mutual fund industry," Management Science, vol. 65, no. 7, pp. 2947-3448, 2018.

[73] M. Kacperczyk and A. Seru, "Fund manager use of public information: new evidence on managerial skills," The Journal of Finance, vol. 62, no. 2, pp. 485-528, 2007.

[74] K. J. M. Cremers and A. Petajisto, "How active is your fund manager? A new measure that predicts performance," Review of Financial Studies, vol. 22, no. 9, pp. 3329-3365, 2009.

[75] Y. Amihud and R. Goyenko, "Mutual Fund'sR2as predictor of performance," Review of Financial Studies, vol. 26, no. 3, pp. 667-694, 2013.

[76] K. Daniel, M. Grinblatt, S. Titman, and R. Wermers, "Measuring mutual fund performance with characteristic-based benchmarks," The Journal of Finance, vol. 52, no. 3, pp. 1035-1058, 1997.

[77] G. Hoberg, N. Kumar, and N. Prabhala, "Mutual fund competition, managerial skill, and alpha persistence," The Review of Financial Studies, vol. 31, no. 5, pp. 1896-1929, 2018.

[78] B. Mullen, C. Johnson, and E. Salas, "Effects of communication network structure: components of positional centrality," Social Networks, vol. 13, no. 2, pp. 169-185, 1991

[79] J. M. Podolny, "A status-based model of market competition," American Journal of Sociology, vol. 98, no. 4, pp. 829-872, 1993.

[80] J. M. Podolny and D. J. Phillips, "The dynamics of organizational status," Industrial and Corporate Change, vol. 5, no. 2, pp. 453-471, 1996.

[81] X. F. Zhang, "Information uncertainty and stock returns," The Journal of Finance, vol. 61, no. 1, pp. 105-137, 2006.

[82] M. Statman, "How many stocks make a diversified portfolio?" The Journal of Financial and Quantitative Analysis, vol. 22, no. 3, pp. 353-363, 1987. 